Foster Friends, Be A Friend, Friendship Families, Canadian Friends, Mes Amis de Partout . . . In almost every Canadian community that took in both private and government-sponsored Southeast Asian refugees, volunteers have come forth to offer governmentsponsored refugees the personal support privatelysponsored refugees receive.

In general, the federal government provides refugees with hotel accommodation when they first arrive, with basic orientation classes on such topics as shopping and banking, and with financial support until the refugees' incomes can meet their basic needs. For many this is sufficient for them to find their way in their new home.

But for every newcomer - from the one who, unable to speak a word of English or French, wanders into a refugee aid agency clutching a scrap of paper, "Somebody please help this man find a place to live", to the one who is independent within a month yet two years later may still have no Canadian friends - some personal contact with members of the older community seems essential to full integration into our society.

In some areas, the Manpower Officers have taken this role on themselves, going into the refugees' homes to show them how to cook cheap meals when they can't make ends meet on their allowance, running English conversation groups, inviting people to dinner in their

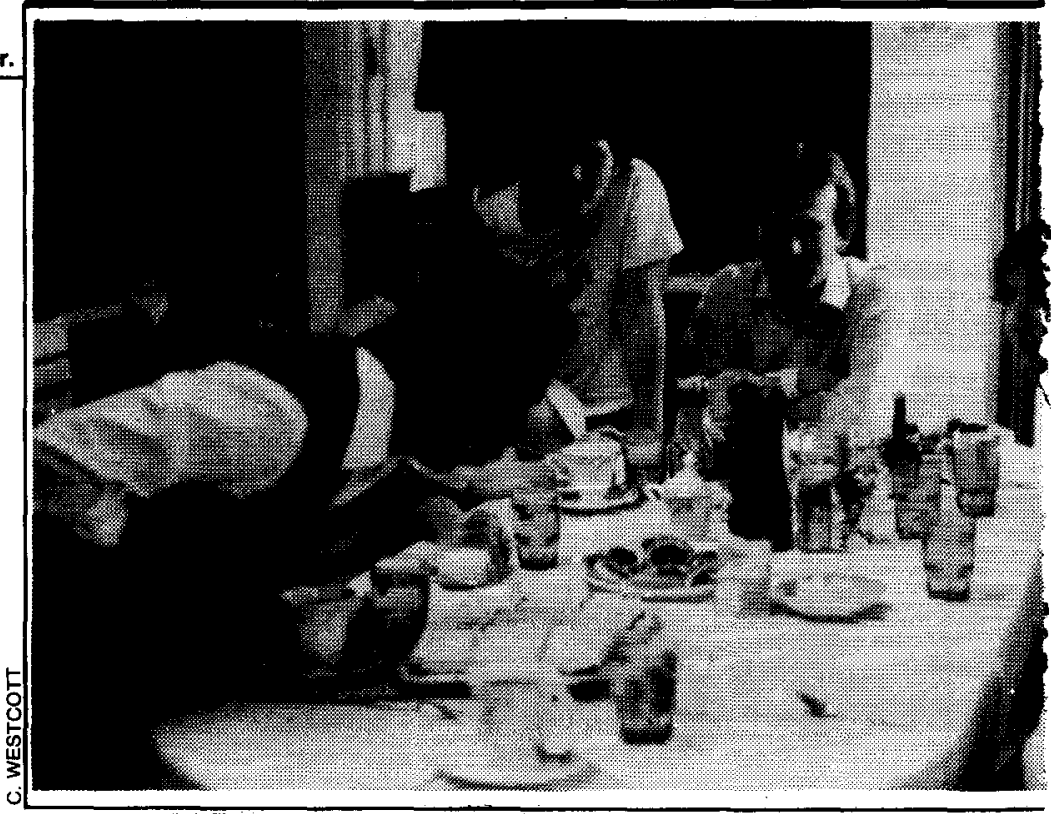

homes. In other cases, sponsors have endeavoured to help the friends of the people they sponsored.

But in many communities, organized volunteer programmes evolved to meet this deficiency. Some of these communities share their experiences here, in the hope that others will share theirs.

\title{
THE FIRST FRIENDSHIP FAMILIES
}

\section{by Vera Arkell, Windsor}

Windsor - the city with the big heart. It is known to give more to charities per capita than any other city in Canada. With equal generosity, Windsor opened its heart to the Southeast Asian refugees.

On March 15, 1978, the "Mayor's Committee for Vietnamese Refugees," an informal group comprising the mayor and a few concerned citizens, met out of growing concern for Indochinese refugees. The group decided to assist twenty families from Indochina to resettle in Windsor. Because of the vast cultural differences between their countries and Canada, and the ordeals they had experienced, we believed that a close, personal association with a Windsor family, person or group of persons would help alleviate the overwhelming task of resettlement.

So the Mayor's Committee established contacts with local church congregations and informed them of the need and ways in which they might help the refugees. The role of the Friendship Family was to befriend the new arrivals in whatever way possible, in order to build a relationship of mutual trust which would support the refugees in their search for identity and acceptance in a new culture. The response of Windsorites was immediate and enthusiastic. In June 1978 a telex from Singapore expressed thanks and stated that Windsor was the leading city in sponsoring refugees.

As we enter mid-1981, we see that this programme did much to cultivate a sense of acceptance and security for the refugees, and to enrich the lives of the people involved. Many Friendship Family groups or individuals have maintained strong ties with the refugees since their arrival almost three years ago. And we believe that the first experiences in Friendship Family responsibilities greatly fostered the efforts at private sponsorship.
FRIENDS, FRIE

\section{SUDBURY FAMILIES WELCOME REFUGEES INTO THEIR HOMES}

by Carole Paré and Tien Hoang, Sudbury Regional Multicultural Centre

Some Canadians may think of Sudbury as an isolated mining community. We like to think of ourselves as the heart of Northern Ontario, a prosperous, modern and very friendly city of 160,000 people. In the past two years, Sudburians have warmly welcomed more than 400 Indochinese refugees, approximately 85 governmentsponsored and 315 privately-sponsored.

The Sudbury Regional Multicultural Centre works closely with Employment and Immigration Canada in coordinating refugee settlement and adaptation. Through our "Home Placement Programme" for governmentsponsored refugees, new arrivals are placed directly with Canadian families until an apartment can be found.

Previously, these people were put into a local hotel and sometimes spent two to three weeks isolated and often very lonely. The Home Placement Programme helps to overcome some of these initial fears and frustrations, because there is someone to help in those first few weeks. And for the refugees, it is also a chance to learn first-hand the Canadian language, culture and way of life. When they arrive they are given a choice of whether to go to a hotel or a house, and no one has yet chosen the hotel.

Each host family is given $\$ 45$ a week per person for room and board, which represents an enormous savings to the government.

This system has been a tremendous success! All of our participating Canadian families have been so pleased with the experience that they have formed lasting 